\title{
Child Poverty Amongst Young Carers in the UK: Prevalence and Trends in the Wake of the Financial Crisis, Economic Downturn and Onset of Austerity
}

\author{
Polly Vizard $^{1}$ (D) Polina Obolenskaya ${ }^{1} \cdot$ Tania Burchardt $^{1}$
}

Accepted: 13 November 2018 / Published online: 14 January 2019

(C) The Author(s) 2019

\begin{abstract}
The article provides the first estimates of prevalence and trends in child poverty amongst young carers aged 5-19 in the UK using specialized income data from the Family Resources Survey / the Households Below Average Income Survey. Looking across four key indicators, we find that child poverty rates were higher amongst young carers than other children based on 3 years pooled data for 2013/14-2015/16. The differences in the prevalence of child poverty amongst young carers and other children are statistically significant in relation to two indicators (anchored low income before housing costs, and a combined measure of low income and material deprivation). Young carers also appear to have fared worse than other children in terms of trends in child poverty outcomes over the period that coincided with the financial crisis, economic downturn and onset of austerity. Amongst young carers, there was a statistically significant increase in relative low income after housing costs of nine percentage points (from 24 to 33\%) between 2005/07 and 2013/15. This compares with a two percentage point decline amongst other children. Multivariate findings confirm that trends in child poverty outcomes amongst young carers were highly differentiated from those of other children and that the association between child poverty and young caring status strengthened over the period under observation. Multivariate analysis further suggests that the increases in child poverty rates amongst young carers were not driven by purely "compositional" factors relating to demographic characteristics of the households in which young carers live and that labour market factors are particularly important in explaining the trends that are observed. Overall, the findings from the study raise concerns that young carers were disproportionately impacted by the patterns of stagnating real income and declining income from employment that characterized the period following the financial crisis, economic downturn and onset of austerity, whilst underlining the importance of
\end{abstract}

Electronic supplementary material The online version of this article (https://doi.org/10.1007/s12187-0189608-6) contains supplementary material, which is available to authorized users.

Polly Vizard

p.a.vizard@1se.ac.uk

Extended author information available on the last page of the article 
housing costs as a factor in child poverty amongst young carers, and raising important questions regarding the ongoing effectiveness of social protection for this group.

Keywords Child poverty · Young carers $\cdot$ Financial crisis $\cdot$ Recession $\cdot$ Austerity

\section{Introduction}

This article examines child poverty outcomes amongst young carers in Britain. We set out new evidence on the prevalence of child poverty amongst young carers and analyse trends over the period that coincided with the financial crisis, economic downturn and onset of austerity. Young carers are children and young people who provide unpaid care for someone who is physically or mentally ill, disabled or who is misusing drugs or alcohol. ${ }^{1}$

Our motivation in writing the paper is three-fold. First, our findings address a gap in social research on young carers. A review of the available international evidence suggests that, globally, there has been increasing awareness and social recognition of unpaid care giving by children and young people as a social phenomenon in both advanced industrial countries and developing countries - and of young carers as a distinct group of dependent children with needs, experiences and outcomes that are differentiated from children in general - over the last 25 years. A small but important body of social research examines this phenomenon and establishes that care giving by children and young people in different countries and contexts can be associated with adverse educational and health outcomes; social isolation and loneliness; bullying and stigmatization; and poor transitions into adulthood (Becker 2007). However, whilst poverty is an important theme and recurrent theme within social research on young carers, to date, there has been little or no systematic research on child poverty outcomes amongst young carers using specialized household income surveys or the child poverty indicators that are used to monitor outcomes amongst other children. Our study addresses this research gap, focusing on the UK context.

Second, the study highlights the importance of cross-fertilisation between research on young carers and research on child poverty, taking forward discussions about the groups of children that should be separately identified and analysed within child poverty research. Internationally, there is increasing emphasis on moving away from population averages and on building up disaggregated evidence on inequalities in social inequalities. For example, the Sustainable Development Goals put more emphasis on breakdowns by characteristics such as gender, ethnicity, nationality, migration status and disability than in the context of the previous Millennium Development Goals. In the British context, there is increasing recognition of the importance of breakdowns by characteristics such as gender, disability status, gender, ethnicity, nationality, migration status, religion and belief and socio-economic status, in national monitoring exercises using social indicators. The Equality and Human Rights Commission has highlighted the need for disaggregated data of this type, including through the development of the Children's Measurement Framework, which provides a mechanism for building up disaggregated evidence on children's equality and human rights outcomes

\footnotetext{
${ }^{1}$ The working definition of a young carer adopted in that article follows that suggested in (Cheesbrough et al. 2017: 6-7). This defines a young carer as: "a child/young person under the age of 18 who provides care in, or outside of, the family home for someone who is physically or mentally ill, disabled or misusing drugs or alcohol. The care provided by children may be long or short term and, when they (and their families) have unmet needs, caring may have an adverse impact on children's health, well-being and transitions into adulthood".
} 
using child level indicators (Clery et al. 2014). Here, we build on and take forward this approach by highlighting the importance and feasibility of breakdowns by young caring status in child poverty research. Whilst our focus is on the UK, the findings highlight the need to challenge the invisibility of young carers in child poverty research more generally.

Third, the study contributes to the growing body of international evidence on the impact of the financial crisis and recession that was experienced in many countries after 2007/8 - and of the subsequent programmes of fiscal consolidation and austerity that were adopted by many Governments in the wake of the financial crisis and recession - on child poverty. Previous and ongoing research efforts aim to build up international evidence in this area include Cantillion et al. (2017) and, within the UK context, recent research includes Stewart and Obolenskaya (2015), Hills and Stewart (2016) and Bradshaw (2017). Some of the most recent literature addresses the question of whether the impact of the crisis, downturn and austerity on child poverty has been equally experienced by all children - with analysis of trends in child poverty outcomes in the wake of the crisis, recession and austerity by characteristics such as lone parent status, ethnicity, disability and social class (EHRC 2015; Bradshaw 2017). Here, we add to the existing literature on the UK experience by providing comparable evidence relating to young carers.

The broader context of the article is the decade of squeezed real incomes and stagnating real wage growth that followed the financial crisis of 2007/8 in the UK, together with public policy emphasis on austerity and fiscal consolidation after 2010. Following the 2010 General Election, the goals of the Coalition Government included eliminating the UK's fiscal deficit with a heavy reliance on public expenditure cuts rather than increased taxation, coupled with a major programme of welfare reform. At the time of writing, ongoing changes in access to, and the generosity of, social protection arrangements include, inter alia, a tax credit and benefit freeze, cuts to taper rates (the amount that can be claimed before a benefit is withdrawn), limits on the number of bedrooms allowed for housing benefit, caps on payments for families with more than two children, changes in eligibility criteria for disability benefits, and other changes associated with the roll out of Universal Credit.

Following substantial improvements in overall child poverty outcomes in the UK in the decade to $2004 / 5$, there was upward pressure on some indicators in the period 2004/5-2007/8 (particularly after housing costs). In the immediate wake of the financial crisis and economic downturn, there were falls in overall relative child poverty before and after housing costs, and overall anchored poverty after housing costs (2008/9-2010/11), whilst overall anchored child poverty before housing costs declined continuously until 2010/11. However, the year 2010/11 is identified as a turning point in the child poverty literature, with progress in addressing child poverty subsequently slowing down or stalling. There were signs of upward year on year pressure on overall anchored poverty before housing costs (in 2011/12), and after housing costs (in 2011/12 and 2012/13), whilst overall relative child poverty increased before and after housing costs in 2014/15 and 2015/16 (ibid; Stewart and Obolenskaya 2015; Bradshaw 2017; DWP 2017a Supporting Table 4_14ts-20ts). Moreover, authoritative forecasts predict a substantial upturn in overall child poverty rates in the UK in the upcoming period (to 2020/21). Much of this predicted increase is attributable to households in receipt of benefit income gaining less from real earnings growth than the general 
population, together with changes to taxation and benefits resulting from ongoing fiscal consolidation measures and the welfare reform programme (Hood and Waters 2017). ${ }^{2}$

Providing robust evidence and analysis of child poverty outcomes amongst young carers is particularly timely and important against this background. Indeed, a substantial proportion of young carers live in households in receipt of welfare benefits and tax credits and many young carers live in households with lone parents or parents or siblings who experience limiting longstanding illness or disabilities, and which are in receipt of disability benefits (on which, see the discussion below). Therefore, there are good reasons to anticipate that ongoing changes to social protection might particularly impact on this group. In the literature on young carers, particular concerns have been raised about the potential adverse impact of changes to standard, severe and enhanced disability premiums as part of arrangements for Universal Credit where young carers live in households with disabled adults. Since children are disregarded as a source of care under these arrangements, these benefits play an important protecting role in reducing the care burden of children, particularly in the context of lone parent families (Royston 2012; Children's Society 2013). ${ }^{3}$

The analysis focuses on the period 2005/6-2015/16 (the most recent data at the time the study was undertaken). We acknowledge that this time window is too early to draw definitive conclusions about the effects of ongoing welfare and disability benefit changes, and of the overall impact of the welfare reform programme, on child poverty outcomes amongst young carers. However, our findings provide a baseline for further research and monitoring in the upcoming period. Government emphasis after 2010 on austerity, fiscal consolidation and welfare reform was caveated with explicit commitments to protect so-called "vulnerable groups". Evaluating the extent to which child poverty outcomes amongst young carers have kept up with outcomes for other children over this period provides an interesting and relevant test case.

The paper is organized as follows. Section 2 provides a brief overview of the literature on young carers in Britain. Section 3 provides details of the methodological framework used for our study including datasets, child poverty measures and statistical analysis. Section 4 reports main findings on the prevalence of child poverty amongst young carers using pooled data for 2013/14$2015 / 16$ (the most recent data available when the study was undertaken). Section 5 examines trends over the period coinciding with the financial crisis, economic downturn and the onset of austerity. Section 6 reports main findings

\footnotetext{
${ }^{2}$ Despite this upward pressure, overall relative child poverty BHC/AHC, and overall anchored child poverty AHC, had not exceeded their 2007/8 rates by 2015/16, whilst overall anchored child poverty BHC was at a historic low.

${ }^{3}$ Ongoing changes to social protection arrangements affecting disabled people are reviewed in Kennedy et al. (2016). Concerns that the ongoing reforms will disproportionately impact on households including individuals with disabilities are highlighted in EHRC (2017: 61-69). A recent Inquiry found indications of "grave and systematic" violations of the rights of disabled people in the context of recent reforms to welfare and social care, especially relating to housing benefit entitlement, eligibility criteria for Personal Independence Payment and the ending of the Independent Living Fund (UN Committee on the Rights of Persons with Disabilities 2016, Kennedy et al. (2016), Jones et al. (2017). Evidence on the regressive impact of tax and welfare reforms since 2010, including adverse impacts on disabled people, lone parents and women, is presented in Portes (2017).
} 
from the multivariate analysis. Section 7 discusses the main findings and makes some further observations. Section 8 concludes.

\section{Young Carers in the UK: A Brief Review}

A growing body of social research examines the characteristics, circumstances and experiences of young carers in the UK as well as the nature, scope and intensity of the caring activities they undertake and their needs for social support. Evidence of adverse differentials in young carers' outcomes in areas such as education, transitions into adulthood, health and emotional wellbeing, and physical safety and security, is discussed within both the qualitative and quantitative literature. Here, we provide a brief review of previous studies and highlight the research gap relating to child poverty.

\subsection{Estimates of the Number of Young Carers in the UK}

The censuses for England and Wales, Scotland and Northern Ireland include specific questions on unpaid caring activities and are widely cited as a basis for estimating the numbers of young carers in the UK. The 2001 censuses indicated that there were 175,000 children and young people under 18 in the United Kingdom providing unpaid care to family, friends or neighbours in 2001 (ONS 2011), whilst Carers Trust report that there were 215,000 in the UK in 2011. ${ }^{4}$ Within England and Wales, there were 149,929 unpaid carers aged between 5 and 18 in 2001, rising to 177,918 at the time of the 2011 Census - an $18.7 \%$ increase. Of these, $142,768(80.2 \%)$ young people provided 1 to 19 hours of care, 19,422 (10.9\%) provided 20 to 49 hours and 15,728 (8.8\%) provided 50 or more hours of unpaid care per week (ONS 2013).

There is increasing recognition that the census under-estimates the true numbers of children providing unpaid care. One explanation is that young carers are often 'hidden from view' - with the provision of unpaid care by children being unrecognized, undisclosed and even concealed. This may particularly be the case when children are providing unpaid caring activities for parents who experience mental health problems and substance dependency. Under-reporting may be a particular concern where adults respond to social survey questions on behalf of children in their households (rather than the questions being posed directly to children themselves) (BBC 2010; Children's Society 2013; HM Government 2008; Clay et al. 2016; Cheesbrough et al. 2017; Aldridge 2018: 158\&161).

Social surveys that ask young people themselves (rather than responding adults) about unpaid caring activities typically result in higher population prevalence estimates. Findings based on the Longitudinal Survey of Young People in England (LSYPE) (which began in 2004 with a cohort of over 15,000 pupils aged 13 and 14) point towards a $4.5 \%$ prevalence rate (Children's Society 2013). More recently, a new question was included in the Crime Survey for England and Wales Survey youth questionnaire which asks young people aged 10-15 about their unpaid caring activities. A further advantage of this instrument is that it explicitly asks young people about the

\footnotetext{
${ }^{4}$ Carers Trust (Personal Communication), using figures from Census 2011 in England, Wales and Northern Ireland and official estimates from the Scottish Government.
} 
help and support they provide for people who misuse drugs and alcohol as well as those who are physically or mentally ill or disabled. Our analysis of this data suggests that young carers make up $4.5 \%$ of children of this age (ONS Crime Survey for England and Wales, 2015/16 secure access dataset). ${ }^{5}$

Findings from a recent specialist large-scale face-to-face quantitative study (Cheesbrough et al. 2017: 7-8) provide new evidence on the nature and scope of the unpaid caring activities undertaken by young carers. This suggests that a majority of young carers aged 5-17 care for someone within the home, with 55\% of these providing care for a mother and $25 \%$ for a sibling. Activities provided include cooking, cleaning, paperwork or helping with chores (78\%), emotional support (57\%) and nursing care (6\%), with 53\% providing around an hour of care a day during the school or college week and $14 \%$ four or more hours a day (rising to $26 \%$ a weekends). Whilst older children and young adults are more likely to undertake caring activities than younger children, there is growing evidence of unpaid caring activities amongst very young children aged five and under (Children's Commissioner 2016).

Aldridge (2018: 157) notes that: "aside from age, few studies .. have focused on other .. characteristics of young carer populations such as social class or ethnicity". Exploratory analysis undertaken as part of our own study suggests that factors associated with being a young carer include having a parent who experiences a limiting longstanding illness or disability, being female, living in a lone parent household, being from a non-professional socio-economic group and living in a household where there are no adults in work (see Online Supplementary Information, Table S5).

\subsection{Outcomes}

There is a growing body of evidence on adverse educational outcomes amongst young carers. Qualitative research and social surveys / depth-interviews with young carers point towards high proportions of young carers having low educational qualifications and experiencing under-engagement in educational activities including lack of concentration, poor homework environments and absences associated with caring activities (e.g. Dearden and Becker 2004; Clay et al. 2016: 43-44). Poor transitions into adulthood and early employment opportunities are highlighted in Becker and Becker (2008).

Quantitative findings using the Longitudinal Survey of Young People in England confirm that young carers have lower educational attainment at GCSE level than other children, and are more likely than the national average to be not in education, employment or training (NEET) between the ages of 16 and 19 (Children's Society 2013). Cheesbrough et al. (2017: 34-55) compare parental reports of attainment,

\footnotetext{
5 The CSEW question reads: "Some people your age provide help or support to people who are physically or mentally ill, disabled or misusing drugs or alcohol. This could be a parent, brother, sister, another relative or someone else. Is there anyone like this who you have to look after on an ongoing basis? This could include people who live with you and people who do not". A further question is included in the Understanding Society youth questionnaire. This asks about the provision for unpaid caring activities for siblings as well as for people with disabilities and other problems ("Some people your age may have to look after other people. This could be a brother or sister, a relative or someone else who is disabled or sick. Is there anyone like this who lives here with you that you have to look after on a regular basis?)" Estimates using this question generate higher prevalence estimates than other data source we have reviewed (with 28.7\% of 10-15 year olds reported undertaking these activities in wave 5 data for 2013-2015).
} 
attendance, lateness, concentration and "being in trouble" amongst young carers and other children. Marked differences are observed in the proportion reporting absenteeism in the 5-11 and 12-15 age groups; in the ability to concentrate at younger ages; and in "falling asleep at school". Our own analysis using Understanding Society' wave 5 data (2013-2015), shows that a greater proportion of young carers among 10 to 15 year olds reported truanting in the last year $(8.4 \%$ ) compared to $6.2 \%$ for all other children, with $6.6 \%$ of young carers reporting having missed school specifically due to caring activities (Vizard et al. 2018: Supplementary Appendix).

On health outcomes, Cheesbrough et al. (2017:39) report that the parents of young carers being less likely to report that their children are in "very good" health. The 2011 Census data confirms that young carers are at higher risk of poor general health than other children (ONS 2013). Joseph et al. (2009) highlight the importance of researching the positive emotional and psychological impacts of caring (e.g. feelings of independence and self-worth) as well as negative impacts (e.g. exposure to stressful situations and feelings of anger and loneliness). Qualitative findings reported in Clay et al. (2016) suggest that both of these dimensions are important and that negative emotional/ psychological impacts include anxiety, stress, tiredness, strain within family relationships and restrictions in social activities and relationships.

In relation to physical safety and security, exposure to bullying emerges as an important theme within qualitative research and depth-interviews (e.g. Clay et al. 2016: 44). Cheesbrough et al. (2017: 33) note that 16\% parents of young carers aged 16 to 17 reported their child being bullied compared to $4 \%$ in the comparison survey. Our own analysis provides evidence of higher prevalence of bullying including (cyber bullying), personal crime (theft or attempted theft, criminal damage to personal property, violence (kicking, hitting/shoving/punching, pushing/shoving, using/hitting with a weapon, physical violence in some other way) and fear of crime amongst young carers compared with other children aged $10-15 .^{6}$

\subsection{The Research Gap on Child Poverty}

Prior to the current study, there has been relatively very little cross-fertilisation between research on young carers and research on child poverty. Associations between low household income and disability, illness, substance dependency and care giving by children and young people have been highlighted in the literature. Household resource limitations have been identified as a possible driver of unpaid care by children; as a characteristic of households that include young carers; and as an important barrier / restriction on social participation amongst young carers (Becker 2007; Becker and Becker 2008: 42; Aldridge 2018:157; Clay et al. 2016: 34). Children's Society (2013) reported that median family income for families including a young carer was $£ 5000$ less than families without a young carer. However, prior to the current research it has not been possible to make systematic comparisons between child poverty outcomes amongst young carers and other children using specialist household income data and / or the child poverty indicators that are widely used in child poverty research. As a

\footnotetext{
${ }^{6}$ See Vizard et al. 2018, Supplementary Appendix (using Understanding Society wave 5 2013-2015 youth questionnaire and ONS Crime Survey for England and Wales 2015/16 secure access dataset youth questionnaire).
} 
result, young carers have been effectively 'invisible' within national child poverty monitoring exercises. ${ }^{7}$

\section{Methods}

We use data from the Family Resources Survey (FRS) and the Households Below Average Income (HBAI) dataset to estimate the prevalence of child poverty amongst young carers compared to other children and to examine trends in child poverty outcomes amongst young carers over the period that coincided with the financial crisis, economic downturn and onset of austerity. The study has been designed to replicate the definitions and methodology used to produce official child poverty statistics as closely as possible whilst extending the evidence base to identify and report on child poverty outcomes amongst young carers. The indicators used in the analysis mirror those set out in the Child Poverty Act (2010) and that have subsequently been used adopted in national monitoring exercises. Whilst the statutory targets established in the Child Poverty Act have now been repealed, annual publication of data is required under the Welfare Reform and Work Act (2016).

\subsection{Datasets}

The analysis was undertaken by linking information on unpaid caring status and age from the Family Resources Survey (FRS) children's data file to household income information contained within the Households Below Average Income (HBAI) dataset. The FRS is a major specialist UK household income survey and is used with the derived HBAI dataset to produce official national income and poverty statistics including national statistics on child poverty. Weights have been applied to the data to account for differential nonresponse. The FRS has a complex survey design and adjusting for this has required access to secure versions of the FRS/HBAI datasets which are available with special permission at the Safe Room at the UK Data Archive. ${ }^{8}$

\subsection{Identifying Caring Status Using the FRS}

Caring status is identified within the FRS dataset based on FRS survey questions that ask about the provision and receipt of help and support on an unpaid basis (that is, not as part of a paid job) by household members (online Supplementary Information: Fig. S1). Respondents are specifically asked whether they (or anyone within the household) provides care for a person who experiences physical or mental ill-health or disability, or problems relating to

\footnotetext{
${ }^{7}$ More progress has been made in the literature on adult unpaid carers, with the relationship between income and unpaid caring activities examined using specialist household income data. E.g. Hutton and Hirst (2001) report findings on the relationship between adult unpaid caring episodes and income using the British Household Panel Survey (c.f. this paper section 5 for further discussion). Brief comments on the low income characteristics of adult unpaid carers were included in the Carers Strategy (HM Government 2008) and Hills et al. (2009: 238-239). More recently, the prevalence of poverty amongst unpaid adult carers is examined using the Family Resources Survey in Aldridge and Hughes (2016).

${ }^{8}$ The analysis uses the STATA 'svy' prefix to account for complex survey design. In order to derive strata and cluster identifiers we have drawn on SAS code provided by DWP. For a discussion of DWP recommended methodology in relation to the FRS / HBAI survey design, see DWP (2014b).
} 
old age, inside or outside of their household on an unpaid basis (that is, not as part of a formal job or contract or voluntary work). Caring activities are not prescriptively defined (DWP 2013) and respondents are shown a show card identifying a range of relevant care giving activities that fall within the scope of the concept of unpaid care. ${ }^{9}$ This data is used for official purposes in the modelling and analysis of benefits such as Carer's Allowance, Disability Living Allowance and Personal Independence Payment (DWP 2013).

\subsection{The Sample of Young Carers}

The sample of young carers was identified by combining FRS survey information on caring status with age information using the FRS children's file. The latter includes records for all children and dependent young people within the households that are included within the FRS main sample (including all children under 16 years of age and young people aged 16 to 19 year olds who are unmarried / non-cohabiting who are in full-time non-advanced education). Individuals identified as carers were included within the sample if (1) their records appeared in the FRS children's file and (2) they are aged 5 years old or above. The upper age of 19 adopted in the analysis is consistent with national child poverty statistics that are published for other children. However, this threshold departs from the standard legal marker of child status (which would be 18 rather than 19) as well as the definition of young carers in the Children and Families Act (2014) and census methodology (Aldridge 2018:157). In relation to the lower age threshold adopted within the analysis, under-fives have been excluded because of low numbers under this threshold. ${ }^{10}$

The sample size achieved ranges from 89 to 152 children aged 5-19 annually, with young carers estimated to make up between 1.1 and $1.5 \%$ of dependent 5-19 year olds each year. We acknowledge that the FRS sample under-estimates the population fraction of young carers compared with census and other survey based estimates discussed above (section 2). For this reason, we do not recommend the use of the FRS as a basis for headcount estimates of population proportions or headcounts of young carers. Rather, we recommend the FRS/HBAI as a means of obtaining the best available estimates of income poverty amongst households that include a young carer. ${ }^{11}$

\footnotetext{
${ }^{9}$ FRS is not a child level social survey. Responding adults (rather than children themselves) fill in the survey questionnaire for dependent children. Whilst FRS asks about a wide range of caring activities, it does not specifically ask about help and support for parents with mental health problems or substance abuse problems. C.f. this paper, footnote 5 .

${ }^{10}$ The Children and Families Act 2014 does not impose a lower age limit on the definition of young carers. Moreover, the phenomenon of unpaid care provision amongst very young children has been highlighted in recent research (e.g. Becker 2007; Carers Trust 2015; Children's Commissioner 2016:13:14/Table 3; Clay et al. 2016).

${ }^{11}$ DWP (2013: 77) confirms that FRS underestimates adult unpaid caring activities compared with the Census. Whereas Census figures indicate that in England and Wales in 2011 the proportion of children aged 5-17 providing unpaid care was $2.1 \%$ of population of that age, our equivalent estimate for England and Wales in 2011/12 using FRS/HBAI is $1.4 \%$ for the same age group. In terms of headcounts, the 2011 Census identifies 177,918 young carers the ages of 5 and 17 in England and Wales (The citation "ONS 2014" has been changed to "DWP, NatCen, ONS(SVSD), 2014a, b, c, d, e, f, g, h" to match the author name/date in the reference list. Please check if the change is fine in this occurrence and modify the subsequent occurrences, if necessary.DWP, NatCen, ONS(SVSD) 2014a, 2014b, 2014c, 2014d, 2014e, 2014f, 2014g, 2014h, Safeguarded 2011 Census data), whereas our average annual estimate for the number of young carers aged 5 to 17 in England and Wales using FRS/HBAI for 2009/10-2011/12 is 130,000. Moreover, as noted in section 2, the census itself is recognised as under-estimating the number and population fraction of young carers.
} 
In order to ensure robust results given relatively small sample size and annual data fluctuations, all analysis is based on pooled 3-years data. Pooled data for three financial years 2013/14, 2014/15 and 2015/16 is expressed as shorthand as '2013/14-2015/16'. Similar shorthand is used to refer to pooled 3-years data for other years.

\subsection{Child Poverty Indicators}

We report on child poverty outcomes using four indicators. The first three of these indicators were set out in the Child Poverty Act (2010) whilst the measure of severe low income and material deprivation has been extensively used in annual HBAI reports. The relative low income indicator captures the proportion of children living in households where net household equivalised income is below $60 \%$ of contemporary median income. The anchored low income indicator captures the proportion of children living in households where net household equivalised income is below $60 \%$ of $2010 / 11$ median income held constant in real terms. The low income and material deprivation indicator captures the proportion of children living in households that experience material deprivation and household income below $70 \%$ of contemporary median income. The severe low income and material deprivation indicator captures the proportion of children living in households that experience material deprivation and household income below $50 \%$ of contemporary median income.

The term 'household income' refers to 'real total net weekly equivalised income'. This is measured after direct taxes and benefits (including disability benefits). Note that this definition of income does not take into account the extra costs of living incurred by disabled people. However, it does include benefits such as Disability Living Allowance, Attendance Allowance and Personal Independence Payments which are intended to contribute towards paying those additional costs. Child poverty outcomes are reported both before housing costs (BHC) and after housing costs (AHC).

See online Supplementary Information (section 2) for further details,

\subsection{Statistical Analysis}

The statistical analysis uses a combination of descriptive and multivariate methods. Descriptive methods are used to estimate child poverty outcomes amongst young carers compared with other children and to build up evidence on trends over time. The prevalence analysis uses all four child poverty indicators using 3 years pooled data for the most recent period that data is available at the time of writing (2013/14-2015/ 16). Trends are examined by comparing child poverty outcomes amongst young carers in 2013/14-2015/16 with those in 2005/06-2007/08, and drawing comparisons with trends in child poverty outcomes amongst other children over the same period. The trends analysis only uses the first two of the child poverty indicators (relative and anchored low income). This is because changes in the definition of material deprivation used within the FRS survey over the period under observation make consistent comparisons more difficult.

For the multivariate analysis, we examine the relationship between child poverty outcomes, time period and young caring status using binary logistic regression 
modelling techniques. Note that the objective of the multivariate analysis is not to build a series of full explanatory models but rather to draw conclusions about the association between child poverty and young caring status - and whether the association between these variables was stronger after the crisis, recession and onset of recession (in 2013/14-2015/16) than before these events (in 2005/06-2007/08) - after controlling for a broad range of demographic / compositional factors and household economic activity. We have developed binary logistic regression models for both of the child poverty indicators used in the trends analysis (relative low income and anchored low income) both before and after housing costs. Each model is run for the young carers sample and for all children aged 5-19; with and without an interaction term between time period and young caring status; and with just demographic / compositional controls, and with additional controls for household economic activity.

A formal statement of the regression equations used in the analysis, together with further details of the coding of the independent variables used in the analysis and further details of the results from different variants of each model, are provided in online Supplementary Information (sections 2 and 3).

\section{The Prevalence of Child Poverty amongst Young Carers}

We begin by reporting our main findings on the prevalence of child poverty amongst young carers compared with other children using the most recent data available when this study was undertaken (using pooled data for 2013/14-2015/16). The findings are summarized in Table 1.

The first indicator of child poverty is relative low income. We find that $21.1 \%$ of young carers experienced relative low income compared with $18.1 \%$ of other children (BHC), and $32.7 \%$ compared with $27.6 \%$ (AHC). The second indicator of child poverty is anchored low income. We find that $22.0 \%$ of young carers experienced anchored low income compared with $17.1 \%$ amongst other children BHC, and $31.6 \%$ compared with $26.6 \% \mathrm{AHC}$. The third indicator of child poverty is combined low income and material deprivation. We find that $16.0 \%$ of young carers experienced combined low income and material deprivation, compared with $12.3 \%$ of other children. The fourth indicator of child poverty is severe low income and material deprivation. Here, we find prevalence rates of $4.8 \%$ and $3.8 \%$ amongst young carers and other children respectively.

Overall, looking across all four child poverty indicators, a general pattern of child poverty rates being higher amongst young carers than for other children emerges from the 2013/14-2015/16 pooled data. The confidence intervals and standard errors associated with the estimates for young carers reported in Table 1 are relatively large because of the ways in which adjustment for complex survey design impacts on uncertainty in relation to the estimates for this group. Nevertheless, two of the differences in child poverty rates between young carers and other children based on pooled data for 2013/14-2015/16 (low income against a fixed threshold $\mathrm{BHC}$, and combined low income and material deprivation) are statistically significant at the $10 \%$ significance level. Moreover, the general picture of the presence of clear differentials in child poverty outcomes amongst young carers compared to other children is reinforced by the findings from the trends analysis reported in the section that follows. 
Table 1 Child poverty outcomes by caring status (children aged 5-19, three-year pooled data 2013/14-2015/ $16, \mathrm{UK})$

\begin{tabular}{|c|c|c|c|c|c|c|c|c|}
\hline & & \multicolumn{2}{|c|}{ Young carers } & \multicolumn{3}{|c|}{ Other children } & \multicolumn{2}{|l|}{ Total } \\
\hline & & $\%$ & $95 \% \mathrm{CI}$ & $\%$ & $95 \% \mathrm{CI}$ & & $\%$ & $95 \% \mathrm{CI}$ \\
\hline \multirow[t]{2}{*}{ Relative low income } & $\mathrm{BHC}$ & 21.1 & {$[15.6,28.0]$} & 18.1 & {$[17.3,19.0]$} & & 18.1 & {$[17.3,19.0]$} \\
\hline & $\mathrm{AHC}$ & 32.7 & {$[26.1,40.1]$} & 27.6 & {$[26.6,28.6]$} & & 27.6 & {$[26.7,28.6]$} \\
\hline \multirow[t]{2}{*}{ Anchored Low income } & $\mathrm{BHC}$ & 22.0 & {$[16.3,29.0]$} & 17.1 & {$[16.3,17.9]$} & $*$ & 17.1 & {$[16.3,18.0]$} \\
\hline & $\mathrm{AHC}$ & 31.6 & {$[25.1,38.9]$} & 26.6 & {$[25.6,27.5]$} & & 26.6 & {$[25.7,27.6]$} \\
\hline $\begin{array}{l}\text { Low income }(\mathrm{BHC}) \text { and } \\
\text { material deprivation }\end{array}$ & & 16.0 & {$[11.2,22.3]$} & 12.3 & {$[11.6,13.0]$} & $*$ & 12.3 & {$[11.7,13.1]$} \\
\hline $\begin{array}{r}\text { Severe low income (BHC) } \\
\text { and material deprivation }\end{array}$ & & 4.8 & {$[2.4,9.5]$} & 3.8 & {$[3.4,4.2]$} & & 3.8 & {$[3.4,4.2]$} \\
\hline
\end{tabular}

Source: Authors' analysis of Family Resources Survey (FRS) and Households below Average Income (HBAI) data (UK data archive study number 7196 - family resources survey and households below average income: safe room access

Notes

a Analysis is based on the FRS/HBAI children's file which covers dependent children aged 0-19. Young children under 5 have been excluded from the analysis because of low numbers of young carers under this threshold

b Years refer to financial years and the FRS/HBAI data has been pooled into three-year periods. '2013/14 2015/16' refers to 3 years of pooled data for financial years 2013/14, 2014/15 and 2015/16

c The income data has been equivalised using a couple with no children as the reference point

d \% - weighted column proportions; $95 \% \mathrm{CI}$ - 95\% confidence interval

e An asterisk(s) denotes a statistically significant difference between the proportion of young carers and noncarers in poverty based on a survey design-based $\mathrm{F}$ statistic test; where $* p<0.10$, ** $p<0.05$, *** $p<0.01$

f $B H C$ Before Housing Costs, AHC After Housing Costs

\section{Trends in Child Poverty Outcomes amongst Young Carers in the Period since the Crisis, Recession and Onset of Austerity}

We now report our main findings on trends in child poverty outcomes amongst young carers over the period that coincided with the financial crisis, economic downturn and onset of recession. These are illustrated in Fig. 1 (rounded up to zero significant figures). Further details are provided in online Supplementary Information (Table S4).

Figure 1, Panel A shows the results for the first indicator of child poverty used in the trends analysis (relative low income). Focusing initially on the left hand side of Panel $\mathrm{A}$, we find that the proportion of young carers experiencing relative low income BHC stood at $18.4 \%$ in $2005 / 06-2007 / 08$, rising to $19.6 \%$ in $2008 / 09-2010 / 11$ in the wake of the financial crisis and recession, before falling back somewhat to $15.5 \%$ in $2010 / 11-2012 / 13$, and rising to $21.1 \%$ in 2013/14-2015/16. These changes amounted to a 2.7 percentage point increase over the period as a whole. Whilst this increase is not statistically significant at the $10 \%$ level, it should be noted that the trends observed amongst young carers contrast sharply with those for other children, amongst whom there was a 4.0 percentage point decline in relative low income $\mathrm{BHC}$ over the same 
(a) Relative low income

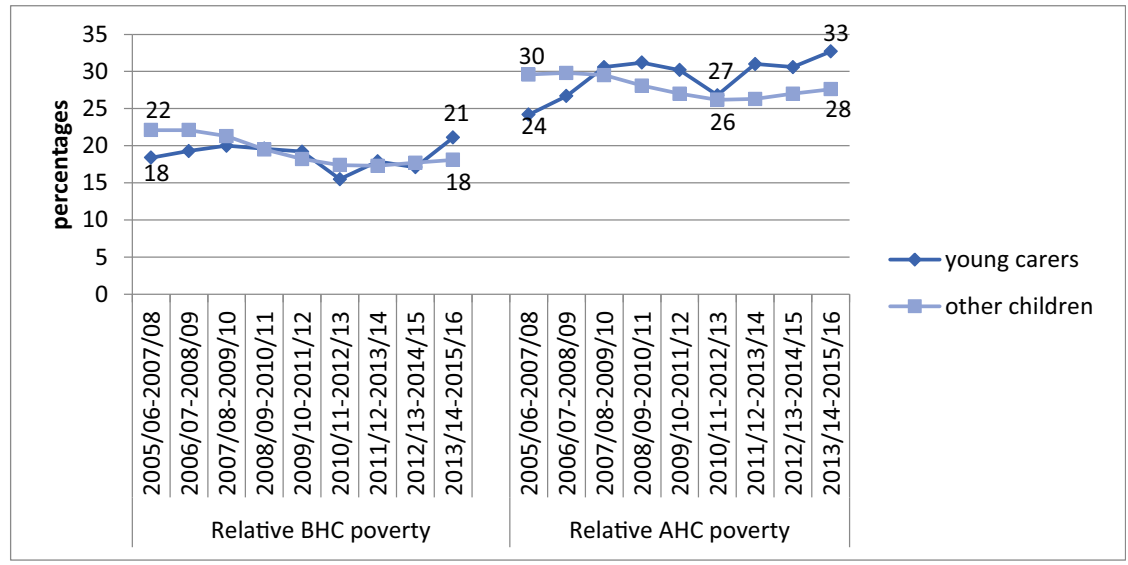

(b) Anchored low income

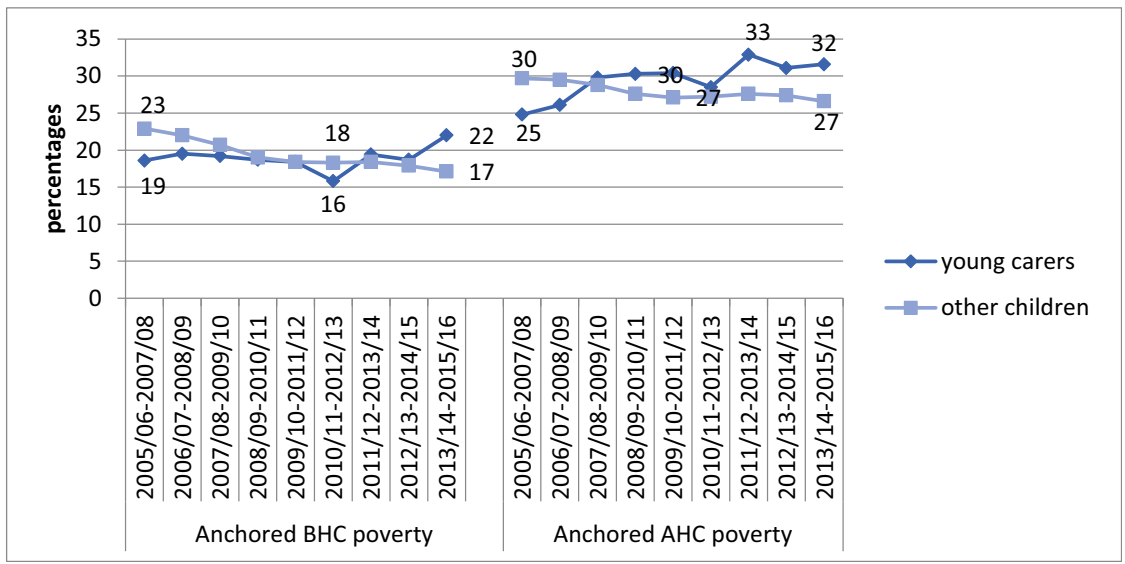

Fig. 1 Child poverty outcomes by caring status (children aged 5-19, 2005/06-2007-2013/14-2015/16, UK) Source: Authors' analysis of Family Resources Survey (FRS) and Households Below Average Income (HBAI) data (UK Data Archive Study Number 7196 - Family Resources Survey and Households Below Average Income: Safe Room Access), weighted proportions. Note: 1. Analysis is based on the FRS/HBAI children's file which covers dependent children aged 0-19. Young children under 5 have been excluded from the analysis because of low numbers of young carers under this threshold. 2. Years refer to financial years and the FRS/HBAI data has been pooled into 3-years periods. For example, 2005/06-2007/08 refers to 3 years of pooled data for financial years 2005/06, 2006/07 and 2007/08. 3. The income data has been equivalised using a couple with no children as the reference point. 4. BHC Before Housing Costs, AHC After Housing Costs

period. This decline is statistically significant at the $1 \%$ level - raising the question of why the improvement in relative low income $\mathrm{BHC}$ amongst children in general over this period was not reflected in child poverty rates amongst young carers.

Turning to the right hand side of Fig. 1, Panel A, we find that the percentage of young carers experiencing relative low income AHC increased from $24.2 \%$ in $2005 / 07$ to $31.2 \%$ in $2008 / 09-2010 / 11$ (this increase is statistically significant at 
the $10 \%$ level). Rates then dipped in 2010/11-2012/13 before climbing up to $32.7 \% 2013 / 14-2015 / 16$ - amounting to a substantial 8.5 percentage point increase over the period as a whole (this increase is statistically significant at the $10 \%$ level). Again, the picture for young carers contrasts sharply with that for other children, amongst whom prevalence rates stood at $29.6 \%$ in $2005 / 07$, falling to $26.2 \%$ in $2010 / 11-2012 / 13$, before increasing to $27.6 \%$ in $2013 / 14$ $2015 / 16$. Overall, these changes amount to a 2.0 percentage point decline between 2005/06-2007/08 and 2013/14-2015/16 (this decline is statistically significant at the $1 \%$ level). These findings again raises the question of why young carers apparently failed to keep up with children in general in terms of their child poverty outcomes.

Panel B shows the results for the anchored low income indicator. On the left hand side of the panel, we see that the proportion of young carers who experienced anchored low income BHC increased between 2005/06-2007/08 and 2013/14-2015/16 from 18.6 to $22.0 \%$ (a 3.4 percentage point increase). In contrast, amongst other children, the proportion experiencing $\mathrm{BHC}$ anchored low income declined by 5.8 percentage points from $22.9 \% 2005 / 06-2007 / 08$ to $17.1 \%$ in $2013 / 14-2015 / 16$. This decline was statistically significant at the $1 \%$ level.

On the right hand side of Panel $\mathrm{B}$, we see that the percentage of young carers who experienced anchored low income AHC increased from 24.8\% in 2005/06$2007 / 08$ to $30.3 \%$ in $2008 / 09-2010 / 11$ and had climbed to $32.9 \%$ by $2011 / 12$ $2013 / 14$ (the increase 2005/06-2007/08-2011/12-2013/14 is statistically significant at the $10 \%$ level). Rates then fell back slightly to $31.6 \%$ in $2013 / 14-2015$ / 16 , amounting to an overall increase of 6.8 percentage points $2005 / 06-2007 / 08-$ 2013/14-2015/16 (note though that this overall increase is not statistically significant at the $10 \%$ level). Amongst other children (excluding young carers), the percentage experiencing $\mathrm{AHC}$ anchored low income declined from $29.7 \%$ in $2005 / 06-2007 / 08$ to $27.6 \%$ in $2008 / 09-2010 / 11$, with a further decline to $26.6 \%$ in $2013 / 14-2015 / 16$ (a 3.1 percentage point decline that is statistically significant $1 \%$ level).

Overall, a general picture emerges of the proportion of young carers experiencing child poverty increasing over the period, whilst the proportion of other children experiencing child poverty remained stable or declined. Whilst some of the changes in the rates of child poverty amongst young carers over the observation window are not statistically significant, the overall picture is one of considerable differentiation in trends in child poverty outcomes amongst young carers and other children, with young carers appearing to have fared substantially worse than other children in terms of trends in child poverty outcomes over the period that coincided with the financial crisis, economic downturn and onset of austerity.

Indeed, the descriptive findings point towards a notable reversal in the position of young carers vis-à-vis other children in relation to their child poverty outcomes within the time window we examine. Prior to the crisis, downturn and onset of austerity, young carers appear to have been relatively well-protected from child poverty (with rates lower than those for other children for both indicators both BHC and AHC). However, by 2013/14-2015/16, child poverty rates were higher amongst young carers than other children according to both 
indicators (both BHC and AHC). The most striking "reversal" relates to relative low income $\mathrm{BHC}$. In relation to this measure, the 4.3 percentage point advantage amongst young carers observed in 2005/06-2007/08 contrasts sharply with the positive and statistically significant adverse difference of 4.9 percentage points in 2013/14-2015/16 (Online Supplementary information: Table S4).

\section{Multivariate Analysis}

We now report main findings from the multivariate analysis. Whilst we focus here on key findings based on the relative low income AHC model, the complete set of multivariate results are provided in online Supplementary Information (Tables S6-S12 and Figs. S3-S4).

Recollect that in the trends analysis (section 5) we observed an intuitively substantial and statistically significant increase in AHC relative low income amongst young carers between 2005/06-2007/08 and 2013/14-2015/16. Table 2 reports four variants of the relative low income $\mathrm{AHC}$ model which enable us to examine the relationships between relative low income $\mathrm{AHC}$, time period and young caring status within a multivariate framework controlling for demographic / compositional factors (age, parental disability, lone parent status / ethnicity / socio-economic group of head of household, UK country of residence) and household economic activity.

Results for the first variant of the relative low income AHC model are summarized under column "Model V1". This specification has relative low income AHC as the dependent variable and time period as the focus independent variable, controlling for the set of demographic / compositional factors, and is run for the sample of young carers. The results show that amongst young carers the odds of relative low income AHC are significantly higher in the second period (2013/14-2015/16) compared to the base year $(2005 / 06-2007 / 08)$ (odds ratio $=1.6, p<0.10)$. This positive and statistically significant odds ratio leads us to conclude that, amongst young carers, there was stronger association between relative low income AHC in 2013/14-2015/16 than in 2005/06-2007/08 after controlling for demographic / compositional factors. This finding also confirms that the increases in the prevalence of relative low income AHC amongst young carers that are observed over the period are not explained by purely demographic / compositional factors such as changes in ethnicity, disability and lone parent status.

Results for the second variant of the relative low income AHC model are summarized in column "Model V2". This specification includes time period, young caring status and the interaction between young caring status and time period as independent variables and is run for the full sample of children aged 5-19. The inclusion of the interaction term enables us to examine the strength of the young caring effect in 2013/14-2015/16 relative to 2005/06-2007/08. The positive and statistically significant interaction term shows that the association between relative low income AHC and being a young carer is differentiated by time period and that this association was stronger in the second period than the first period (odds ratio $=2.2, p<0.01$ ). Alternatively, the positive and significant interaction term shows that the change in child poverty between the two period was more pronounced amongst young carers than other children. This finding provides a powerful confirmation that the association between relative low income AHC and young caring status strengthened in the wake of the crisis, economic downturn and 
Table 2 The association between relative low income (AHC) and time period, controlling for demographic / compositional factors and household economic activity, 2005/06-2007/08 and 2013/14-2015/16, UK)

Odds ratios

$\begin{array}{llll}\text { Model V1 } & \text { Model V2 } & \text { Model V3 } & \text { Model V4 } \\ \text { Young } & \text { All children aged } & \text { Young } & \text { All children aged } \\ \text { carers aged } & \text { 5-19 (interaction } & \text { carers aged } & \text { 5-19 (interaction } \\ \text { 5-19 } & \text { model) } & 5-19 & \text { model) } \\ \text { Controls for demographic / } & \text { Controls for demographic / } \\ \text { compositional factors } & \text { compositional factors and } \\ & & \text { household economic activity }\end{array}$

TIME PERIOD (2005/06-2007/08 - ref)

\begin{tabular}{|c|c|c|c|c|}
\hline 2013/14-2015/16 & $1.596^{*}$ & $1.068^{*}$ & 1.17 & 0.949 \\
\hline & {$[0.437]$} & {$[0.0387]$} & {$[0.350]$} & {$[0.0362]$} \\
\hline $\begin{array}{l}\text { CARING STATUS (all other } \\
\text { children - ref) }\end{array}$ & & & & \\
\hline Young carers & & $0.429 * * *$ & & $0.417 * * *$ \\
\hline & & {$[0.0819]$} & & {$[0.0775]$} \\
\hline INTERACTION TIME / CARING & & $2.204 * * *$ & & 1.535 \\
\hline $\begin{array}{l}\text { STATUS (2013/14-2015/16 \# young } \\
\text { carer) }\end{array}$ & & {$[0.612]$} & & {$[0.441]$} \\
\hline ETHNIC GROUP (White - ref) & & & & \\
\hline Non-white & 1.521 & $2.265^{* * *}$ & 1.417 & $1.902 * * *$ \\
\hline & {$[0.537]$} & {$[0.109]$} & {$[0.495]$} & [0.0932] \\
\hline AGE (5-15 years old - ref) & & & & \\
\hline 16-17 years old & 1.293 & $1.145^{* * *}$ & 1.246 & $1.233 * * *$ \\
\hline & {$[0.292]$} & {$[0.0395]$} & {$[0.291]$} & {$[0.0453]$} \\
\hline 18-19 years old & 0.735 & $1.124^{*}$ & 0.646 & $1.211 * * *$ \\
\hline & {$[0.249]$} & [0.0709] & {$[0.233]$} & {$[0.0795]$} \\
\hline FAMILY TYPE (couple - ref) & & & & \\
\hline Single parent & 1.314 & $1.715^{* * *}$ & 0.986 & $1.732 * * *$ \\
\hline & {$[0.320]$} & {$[0.0618]$} & {$[0.267]$} & {$[0.0727]$} \\
\hline $\begin{array}{l}\text { SOCIO-ECONOMIC } \\
\text { CLASSIFICATION OF } \\
\text { HOUSEHOLD REFERENCE } \\
\text { PERSON (higher manag/admin/ } \\
\text { professional - ref) }\end{array}$ & & & & \\
\hline Intermediate occupations & 1.505 & $3.614 * * *$ & 1.592 & $3.547 * * *$ \\
\hline & {$[0.637]$} & {$[0.184]$} & {$[0.693]$} & [0.189] \\
\hline Routine \& manual & 1.442 & $3.995 * * *$ & 1.32 & $3.294 * * *$ \\
\hline & {$[0.466]$} & {$[0.175]$} & {$[0.440]$} & {$[0.148]$} \\
\hline Never worked/long-term unemployed & 2.14 & $16.19 * * *$ & 1.032 & $4.289 * * *$ \\
\hline & [1.112] & {$[1.440]$} & {$[0.583]$} & [0.431] \\
\hline Not classified/inadequately stated/- & 2.018 & $10.80 * * *$ & 0.826 & $3.070 * * *$ \\
\hline missing & {$[0.905]$} & {$[0.707]$} & {$[0.388]$} & {$[0.236]$} \\
\hline $\begin{array}{l}\text { PARENTAL DISABILITY (LLID) } \\
\text { (parent not disabled - ref) }\end{array}$ & & & & \\
\hline Parent disabled & $2.473 * * *$ & $1.397 * * *$ & $1.686^{*}$ & 0.981 \\
\hline & {$[0.661]$} & {$[0.0561]$} & {$[0.471]$} & {$[0.0427]$} \\
\hline
\end{tabular}


Table 2 (continued)

Odds ratios

$\begin{array}{llll}\text { Model V1 } & \text { Model V2 } & \text { Model V3 } & \text { Model V4 } \\ \text { Young } & \text { All children aged } & \text { Young } & \text { All children aged } \\ \text { carers aged } & \text { 5-19 (interaction } & \text { carers aged } & \text { 5-19 (interaction } \\ \text { 5-19 } & \text { model) } & 5-19 & \text { model) } \\ \text { Controls for demographic / } & \begin{array}{l}\text { Controls for demographic / } \\ \text { compositional factors }\end{array} & \begin{array}{l}\text { compositional factors and } \\ \text { household economic activity }\end{array}\end{array}$

$\begin{array}{lllll}\text { COUNTRY (England - ref) } & & & \\ \text { Wales } & 0.996 & 1.148^{*} & 1.017 & 1.110 \\ & {[0.668]} & {[0.0815]} & {[0.652]} & {[0.0820]} \\ \text { Scotland } & 0.719 & 0.742^{* * *} & 0.785 & 0.757^{* * *} \\ & {[0.228]} & {[0.0351]} & {[0.251]} & {[0.0392]} \\ \text { Northern Ireland } & 0.723 & 0.829 * * * & 0.692 & 0.754^{* * *} \\ & {[0.287]} & {[0.0484]} & {[0.279]} & {[0.0460]} \\ \text { HOUSEHOLD ECONOMIC } & & & & \\ \text { ACTIVITY (all adults in } & & & & \\ \text { work - ref) } & & & 2.045^{* *} & 3.996^{* * *} \\ \text { At least one adult in work } & & & {[0.695]} & {[0.165]} \\ & & 5.566^{* * * *} & 8.747^{* * * *} \\ \text { No adult in work } & & 54,142 & {[2.311]} & {[0.554]} \\ & & & 720 & 54,142 \\ \text { Unweighted observations } & 720 & & & \end{array}$

Source: Authors' analysis of Family Resources Survey (FRS) and Households Below Average Income (HBAI) data (UK Data Archive Study Number 7196 - Family Resources Survey and Households Below Average Income: Safe Room Access)

Notes

a Analysis is based on the FRS/HBAI children's file which covers dependent children aged 0-19. Young children under 5 have been excluded from the analysis because of low numbers of young carers under this threshold.3. The income data has been equivalised using a couple with no children as the reference point

b Years refer to financial years and the FRS/HBAI data has been pooled into three-year periods. For example, 2005/07 refers to 3 years of pooled data for financial years 2005/06, 2006/07 and 2007/08

c For further information on the identification and definition of disability, including issues relating to consistency over time, see DWP (2017b)

d Variable names are in bold/capitals and reference groups are labelled in bold/lower case

e Exponentiated coefficients; Standard errors in brackets: ${ }^{*} p<0.10,{ }^{* *} p<0.05,{ }^{* * *} p<0.01$

f $B H C$ Before Housing Costs, $A H C$ After Housing Costs

$\mathrm{g}$ Intercept/constant estimate has been withheld in order to comply with the conditions of access to Safe Room datasets imposed by UK Data Service

onset of austerity - even after controlling for a range of demographic / compositional factors.

A more intuitive way of understanding this finding is in the metric of predicted probabilities. Amongst young carers, the predicted probability of relative AHC poverty increased from 0.16 to 0.28 over the period (a change of 0.12 ). Amongst other children, the predicted probability of relative AHC poverty increased from 0.28 to 0.29 (a change 
of 0.01). Looking at the marginal effects of interaction term, the increase in the predicted probability of relative AHC poverty amongst young carers was significantly greater than that amongst other children, after controlling for a range of demographic/ compositional factors (see online Supplementary Information, Table S11 and Fig. S3).

Results for the remaining two variants of the relative low income AHC model are summarized in columns "Model V3" and "Model V4". "Model V3" is a young carers' model that is similar to "Model V1" but which includes household economic activity as well as the set of demographic / compositional factors as an additional control. The results show the statistically significant association between AHC relative low income and time period is not observed once household economic status is accounted for (odds ratio $=1.2$ ). "Model V4" is an interaction model that includes the additional control for household economic activity but which is otherwise similar to "Model V2". Again, the results show that with the inclusion of household economic activity as an additional control variable the picture changes and that the interaction of young caring status and time period is no longer observed to be statistically significant (odds ratio $=1.5$ ). Both variants point towards the importance of household economic activity as an explanatory factor in understanding child poverty outcomes with the odds of experiencing child poverty being substantially higher when there are no working adults in the households in work (vs all in work) compared to households with at least one working adult (vs all in work) (odds ratios of 5.6 and 8.8 respectively).

Overall, the multivariate findings confirm that child poverty outcomes amongst young carers were highly differentiated from those of other children over the period under observation; that the increases in relative low income AHC rates amongst young carers were not driven by purely "compositional" factors relating to demographic characteristics of the households in which young carers live; that labour market factors are particularly important in explaining the trends that are observed. The interaction models provide a powerful confirmation that caring status matters independently from other characteristics, except labour market status; that the association between relative low income poverty AHC and young caring status strengthened over the period; and that the difference in poverty trends between young carers and other children is substantial.

\section{Discussion and Further Observations ${ }^{12}$}

Our findings raise important questions about why young carers appear to have fared so much worse than other children in terms of their child poverty outcomes over the period since the crisis, downturn and onset of austerity. Nationally, there are major concerns about a housing crisis, with housing shortages and high housing costs relative to average incomes in many areas. As Belfield et al. (2015: p.31) note, whilst general population housing costs have fallen in recent years due to the fall in interest rates for mortgages, low income households are less likely to be living in owner-occupied accommodation and to have benefited from this trend. The findings confirm the importance of these differential trends in housing costs by tenure, with increases in housing costs for private and social renters. The proportion of young carers living in privately rented accommodation climbed from $10 \%$ in $2005 / 06 / 2007 / 08$ to $20 \%$ in $2010 / 11-2012 / 13$, before falling back to $13 \%$ in 2013/14-2015/ 16. Amongst other children, there was a sustained increase in private renters from 11 to $18 \%$.

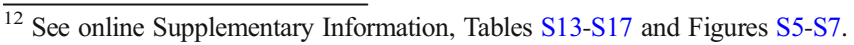


Yet whilst housing costs are an important factor, $\mathrm{BHC}$ household income has been slower to recover after the crisis and economic downturn amongst young carers than other children. Whilst the real income squeeze associated with the economic downturn affected all children across the overall income distribution (that is, at the 10th, 50th and 90th percentiles), young carers were particularly hard hit. BHC household median income had failed to recover to pre-crisis (2005/06-2007/08) levels by 2013/14-2015/ 16 amongst young carers, whereas amongst other children median income had begun to rise again towards the end of the observation window.

Unravelling trends in sources of BHC income is complex. Our analysis suggests that young carer households were disproportionately impacted by the patterns of declining and stagnating income from employment in the wake of the financial crisis, economic downturn and onset of austerity, and may have also been impacted by declines in disability benefit. The proportion of young carers living in households with no adults in work stood at $25 \%$ in $2005 / 06-2007 / 08$, increasing to $30.4 \%$ in $2013 / 14-2015 / 16$, whilst the proportion of other children living in workless households remained relatively flat (at $15 \%$ in 2005/06-2007/08 and 13\% in 2013/14-2015/16). Stagnating real wages were also a feature of the recession and downturn period and some social groups were disproportionately affected (Hills et al. 2015; Vizard et al. 2015). Median real household income from earnings (employment and self-employment) decreased amongst all children between 2005/06-2007/08 and 2013/14-2015/16. This decline was particularly pronounced in the households of young carers, with a $22 \%$ fall in household income from earnings over the period. The proportion of households in receipt of any income from employment changed from 77 to $68 \%$ for young carers and from 84 to $86 \%$ for other children. The share of total household income from employment fell over the period for young carers from 69 to $62 \%$ whilst remaining stable amongst other children (with figures of $81 \%$ and $80 \%$ ).

The social security system is intended to play a compensatory role when sources of income from employment decline. In line with this expectation, the share of state support in household income increased over the period, with young carers living in households that were more reliant on benefits and tax credits (and less reliant on employment income) in 2013/14-2015/16 than their counterparts in 2005/06-2007/08. Median total real income from state support also increased, however, by a substantially smaller percentage amongst young carers that other children (with increases of $20 \%$ and $48 \%$ ). Irrespective of caring status, $98 \%$ of children lived in households in receipt of state support (including benefits, Child Benefit and tax credits) in 2005/06-2007/08. By 2013/14-2015/16, these proportions had fallen, to $94 \%$ of young carers and $88 \%$ of other children.

Looking at trends in receipts of disability benefit separately, the percentage of young carers living in households that received at least one disability benefit stood at $51 \%$ in $2005 / 06-2007 / 08$, increasing to $62 \%$ in $2011 / 12-2013 / 14$, before falling to $59 \%$ in 2013/14-2015/16 (the corresponding figures for other children are 11, 12 and 12\%) (online Supplementary Information, Table S14). There was a substantial increase in the proportion of young carers living in households that were in receipt of income replacement related disability benefits, with a 15 percentage point increase in the proportion receiving benefit income from Employment Support Allowance and Incapacity Benefits, compared with a 4 percentage point increase in the proportion receiving 'other disability' benefits (such as Personal Independence Payment, Disability Living Allowance, Severe Disablement Allowance and / or Attendance Allowance). Median real household income from disability benefits increased by $10 \%$ amongst young carers, whilst declining by $8 \%$ among all other 
children. However, if Incapacity Benefit and Employment and Support Allowance are excluded from the calculation of income from 'disability benefits', median real income from 'other disability benefits' amongst young carers shows a substantial (15\%) decline, with an increase of $7 \%$ among all other children.

The emergence of a substantial child poverty gap between young carers and other children in 2013/14-2015/2016 raises important questions about the overall effectiveness of social protection mechanisms towards the end of the period under observation. Previous research examining the relationship between unpaid adult caring and household income using the British Household Panel Survey concluded that whilst caring episodes were associated with lower income from employment, there was little difference in household income between adult carers and non-carers, and benefit receipts and pensions played an important compensatory role. Whilst recognizing that this analysis did not account for the additional costs of disability, the authors concluded that an important lesson from this research was that the social protection system was playing an important protective role (Hutton and Hirst 2001). Our own pre-crisis findings are consistent with these conclusions, with young carers apparently being relatively well protected from child poverty in 2005/06-2007/08. However, in 2013/14-2015/2016, the effectiveness of state support in protecting young carers from child poverty appears to have weakened substantially.

\section{Conclusions}

The analysis in this article enhances previous knowledge and understanding in three key ways. First, our findings add to the literature on young carers by providing robust evidence showing that child poverty outcomes among young carers are strongly differentiated from those of other children. Second, our findings add to the literature on child poverty by highlighting the importance of an additional group (young carers) in child poverty research and adding to the evidence on child poverty outcomes amongst "vulnerable" groups in the wake of the financial crisis, economic downturn and onset of austerity. Third, our findings highlight the benefits of cross-fertilisation between young carers research on the one hand, and child poverty research on the other, by establishing the importance and feasibility of identifying, monitoring and reporting on the position of young carers using child poverty indicators.

The empirical findings from our study raise concerns that young carers have been disproportionately impacted by the patterns of stagnating real income and declining income from employment that have characterized the period since the financial crisis, economic downturn and onset of austerity, as well as raising concerns about social protection and underlining the role of housing costs. The descriptive findings suggest that child poverty was higher amongst young carers than other children in the most recent 3 years for which data is available when the study was undertaken (pooled data for 2013/14-2015/16). Moreover, there were marked differences in trends amongst young carers and other children over the period under observation (comparing outcomes in 2013/14-2015/16 with those in 2005/06-2007/08). Young carers appear to have fared substantially worse in terms of trends in child poverty outcomes in the wake of the financial crisis, recession and onset of austerity, failing to share the continued improvements experienced by other children in terms of their child poverty outcomes over the period under observation. Our multivariate findings provide a powerful confirmation of the differential nature of trends amongst young carers 
as a group, as well as confirming that the association between child poverty and young caring status strengthened between 2005/06-2007/08 and 2013/14-2015/16 that the trends observed are not explained by demographic / compositional factors such as ethnicity, lone parent status and parent disability; and that labour market factors played an important role.

Given authoritative forecasts of a substantial upturn in overall child poverty rates in the upcoming period, it is critical that further research is undertaken to update these findings and evaluate child poverty outcomes amongst young carers in the upcoming period. To support this ongoing research, we recommend that questions on unpaid care are continued to be included within the FRS and that due attention is given to sample size. At a more technical level, our analysis in this article shows that methodological adjustments for complex survey design are resulting in a substantial widening of uncertainty around statistical point estimates of child poverty amongst young carers. To address this issue, we recommend that data providers consider the implications of complex survey design for monitoring child poverty outcomes amongst groups where numbers are relatively low.

Finally, as well as encouraging ongoing monitoring and reporting of child poverty outcomes amongst young carers in the upcoming period in the UK, we hope that the evidence and analysis here provides a model for challenging the invisibility of young carers within child poverty statistics internationally. As a basis for this, and building on the FRS prototype, we also recommend the inclusion of questions that support the identification of young carers within all national household income surveys.

Acknowledgements The Nuffield Foundation has funded this project, but the views expressed are those of the authors and not necessarily those of the Foundation. More information is available at www. nuffieldfoundation.org. We are very grateful to the Foundation for its support, and to Tracey Budd, Teresa Williams and Ruthe Maisey for their guidance, advice and support. We would also like to thank DWP for approving access to the safe room version of the Family Resources Survey / Households Below Average Income survey and the UK Data Service Support team for their efficient continued support with data analysis and clearance. Dawn McDonagh (HBAI team) provided very helpful guidance relating to complex survey design adjustments. We are grateful to the project Advisory Group for their comments and input. Earlier drafts of the paper benefitted greatly from comments from Peter Matejic (DWP), Chloe Alexander (formerly The Carers Trust) and Ruth Maisey (Nuffield Foundation). Eleni Karagiannaki from CASE has provided helpful comments and methodological guidance throughout the project, for which we are extremely grateful. Responsibility for for errors of fact or interpretation remains with the authors.

Open Access This article is distributed under the terms of the Creative Commons Attribution 4.0 International License (http://creativecommons.org/licenses/by/4.0/), which permits unrestricted use, distribution, and reproduction in any medium, provided you give appropriate credit to the original author(s) and the source, provide a link to the Creative Commons license, and indicate if changes were made.

Publisher's Note Springer Nature remains neutral with regard to jurisdictional claims in published maps and institutional affiliations.

\section{References}

Aldridge, H., \& Hughes, C. (2016). Informal carers and poverty in the UK: An analysis of the Family Resources Survey. New Policy Institute. https://www.npi.org.uk/publications/income-andpoverty/informal-care-and-povertyuk/. Accessed 15/12/2018.

Aldridge, J. (2018). Where are we now? Twenty-five years of research, policy and practice on young carers. Critical Social Policy, 38(1), 155-165. 
BBC (2010). Hidden army of young carers could be four times as high as official figures. http://www.bbc.co. uk/pressoffice/pressreleases/stories/2010/11_november/16/carers.shtml. Accessed 30/12/2017.

Becker, S. (2007). Global perspectives on Children's unpaid caregiving in the family: Research and policy on 'young Carers' in the UK, Australia, the USA and sub-Saharan Africa. Global Social Policy, 7(1), 23-50.

Becker, F. and Becker S. (2008). Young adult carers in the UK: Experiences, needs and services for carers aged 16-24. The princess royal trust for carers. http://static.carers.org/files/yac20report-final-2410083787.pdf. Accessed 30/12/2017.

Belfield, C. Cribb, J., Hood, A., \& Joyce, R. Living Standards, Poverty and Inequality in the UK: 2015. Available at https://www.ifs.org.uk/uploads/publications/comms/R107.pdf. Accessed 14/12/2018.

Bradshaw, J. (2017). The UK. In B. Cantillion, C. Yekaterina, H. Sudhanshu, and B. Nolan Children of austerity: the impact of the great recession on child poverty in rich countries. UNICEF.

Cantillion, B., Yekaterina C., Sudhanshu H., and Nolan B., (2017). Op. cit.

Carers Trust (2015). Supporting young carers aged 5-8. https://professionals.carers.org/supporting-youngcarers-aged-5-8. Accessed 30/12/2017.

Cheesbrough, S., Harding, C., Webster, H., Taylor, L., Aldridge, J. (2017). The lives of young carers in England Omnibus Survey Report. https://www.gov.uk/government/uploads/system/uploads/attachment_data/file/582575 /Lives_of_young_carers_in_England_Omnibus_research_report.pdf. Accessed 30/12/2017.

Children's Commissioner (2016). The support provided to young carers in England. https://www. childrenscommissioner.gov.uk/wp-content/uploads/2017/06/Young-Carers-report-December-2016.pdf. Accessed 30/12/2017.

Children and Families Act. (2014). Available at http://www.legislation.gov.uk/ukpga/2014/6/section/96 /enacted?view=plain. Accessed 14/12/2018

Child Poverty Act. (2010). Available at https://www.legislation.gov.uk/ukpga/2010/9/content. Accessed 14/12 $/ 2018$

Children's Society (2013). Hidden from view: The experiences of young carers in England. http://childrenssociety.org.uk/sites/default/files/tcs/report_hidden-from-view_young-carers_final.pdf. Accessed 30/12/2017.

Clay, D., Connors, C., Day, N. Gkiza, M. Aldridge, J. (2016). The lives of young carers in England. https:/www.gov.uk/government/uploads/system/uploads/attachment data/file/498115/DFE-RR499 The_lives_of_young_carers_in_England.pdf. Accessed 30/12/2017.

Clery, C., Tsang, T., Vizard, P. (2014). The Children's measurement framework: A new indicator-based tool for monitoring children's equality and human rights. Child Indicators Research.

Dearden, C., \& Becker, S. (2004). Young carers in the UK: The 2004 Report. Carers UK and Children's Society. http://www.lboro.ac.uk/microsites/socialsciences/ycrg/youngCarersDownload/YCReport2004 \%5B1\%5D.pdf. Accessed 30/12/2017.

DWP (2013). Family resources survey: 2011/12 https:/www.gov.uk/government/statistics/family-resourcessurvey-201112. Accessed 15/12/2018.

DWP (2014a). Statistical notice. https://www.gov.uk/government/uploads/system/uploads/attachment data/file/275575/hbai-statistical-notice.pdf. Accessed 30/12/2017.

DWP (2014b). Uncertainty in family resources survey-based analysis. https://www.gov. uk/government/uploads/system/uploads/attachment_data/file/321821/uncertainty-family-resourcessurvey-based-analysis.pdf. Accessed 30/12/2017.

DWP (2016). Statistical notice. DWP Family and household income statistics - adjusting for inflation. https://www.gov.uk/government/uploads/system/uploads/attachment_data/file/519332/dwp-familyhousehold-income-stats-adjusting-for-inflation-statistical-notice.pdf. Accessed 30/12/2017.

DWP (2017a). Households below average income: 1994/95 to 2015/16. Main report and supplementary excel tables. https://www.gov.uk/government/statistics/households-below-average-income-199495-to-201516. Accessed 30/12/2017.

DWP (2017b) Households below average income (HBAI) quality and methodology information report 2015/16. https://www.gov.uk/government/uploads/system/uploads/attachment_data/file/599163 /households-below-average-income-quality-metholodogy-2015-2016.pdf. Accessed 17/1/2018.

EHRC (2015). Is Britain fairer evidence series: Domain F: Standard of living evidence paper and child poverty data sheet. https:/www.equalityhumanrights.com/en/britain-fairer/britain-fairer-report/supportingevidence/standard-living-domain. Accessed 30/12/2017.

EHRC (2017). Being disabled in Britain: A journey less equal. https://www.equalityhumanrights. com/sites/default/files/being-disabled-in-britain.pdf. Accessed 30/12/2017.

Hills J, Cunliffe J, Obolenskaya, P., \& Karagiannaki, E. (2015). Falling behind, getting ahead: The changing structure of inequality in the UK, 2007-2013. http://sticerd.lse.ac.uk/dps/case/spcc/rr05.pdf. Accessed 30 /12/2017. 
Hills, J., \& Stewart, K. (2016). Socioeconomic inequalities. In R. Lupton, T. Burchardt, J. Hills, K. Stewart, \& P. Vizard (Eds.), Social Policy in a Cold Climate: Policies and their consequences since the crisis. Bristol: Policy Press.

HM Government. (2008). Carers at the heart of 21st century families and communities. https://www.gov. uk/government/uploads/system/uploads/attachment_data/file/213804/dh_122393.pdf. Accessed 30/12 $/ 2017$.

Hutton, S., \& Hirst, M. (2001). Informal Care Over Time: research works summary, based on the report Caring relationships over time. www.york.ac.uk/inst/spru/pubs/rworks/aug2001.pdf. Accessed 15/12/2018.

Hood, A., \& Waters, T. (2017). Living standards, poverty and inequality in the UK 2016/2017-20201/22. https://www.ifs.org.uk/uploads/publications/comms/R127.pdf. Accessed 30/12/2017.

Jones, A., Wilson, W., Jarett, T., Kennedy, S., \& Powell, A. (2017). The UN inquiry into the rights of people with disabilities in the UK. House of commons library briefing paper. http://researchbriefings.files. parliament.uk/documents/CBP-7367/CBP-7367.pdf. Accessed 30/12/2017.

Joseph, S., Becker, S., \& Becker, F. (2009). Manual for measures of caring activities and outcomes for children and young people. The princess royal trust for carers / University of Nottingham. http://static.carers. org/files/4089-yc-outcomes-manual-spreads-sb-6261.pdf. Accessed 30/12/2017.

Kennedy, S., Murphy, C., \& Wilson, W. (2016). Welfare reform and disabled people. House of commons briefing paper. http://researchbriefings.parliament.uk/ResearchBriefing/Summary/CBP-7571. Accessed $30 / 12 / 2017$.

ONS. (2011). Personal Communication.

ONS (2013). Providing unpaid care may have an adverse effect on young carers' general health. http://webarchive.nationalarchives.gov.uk/20160107063943/. http://www.ons.gov. uk/ons/rel/census/2011-census/detailed-characteristics-for-local-authorities-in-england-and-wales/styyoung-unpaid-care.html. Accessed 30/12/2017.

Portes, J., \& Reed, H. (2017), Distributional results for the impact of tax and welfare reforms between 201017, modelled in the 2021/22 tax year. EHRC Report. https://www.equalityhumanrights. com/sites/default/files/impact-of-tax-and-welfare-reforms-2010-2017-interim-report_0.pdf. Accessed 30 $/ 12 / 2017$.

Royston, S. (2012). Understanding universal credit. Journal of Poverty and Social Justice, 20(1), 69-86.

Stewart, K., \& Obolenskaya, P. (2015). The Coalition's Record on the Under Fives: Policy, Spending and Outcomes 2010-2015. http://sticerd.lse.ac.uk/dps/case/spcc/WP12.pdf. Accessed 14/12/2018

UN Committee on the Rights of Persons with Disabilities (2016). Inquiry concerning the United Kingdom. http://tbinternet.ohchr.org/_layouts/treatybodyexternal/Download.aspx?symbolno=CRPD $\% 2 \mathrm{fC} \% 2 \mathrm{f} 15$ $\% 2 \mathrm{fR} .2 \% 2$ fRev.1\&Lang=en. Accessed 30/12/2017.

Vizard, P., Obolenskaya, P., Karagiannaki, K., Cunliffe, J., Thomson, S., Grollman, C., Lupton, R. (2015). The changing anatomy of economic inequality in London 2007-2013. http://sticerd.1se.ac. uk/dps/case/spcc/rr06.pdf. Accessed 7.18.17.

Vizard, P., Burchardt, T., Obolenskaya, P., Shutes, I., \& Battaglini, M. (2018). Child poverty and multidimensional disadvantage: Tackling "data exclusion" and extending the evidence base on "missing" and "invisible” children. CASEreport 114 and supplementary online appendix. http://sticerd.lse.ac.uk/case/_ new/research/equality/multidimensional_child_poverty/default.asp. Accessed 10/4/2018.

Welfare Reform and Work Act. (2016). Available at http://www.legislation.gov.uk/ukpga/2016 /7/contents/enacted. Accessed 14/12/2018.

\section{Dataset acknowledgements}

DWP, NatCen, ONS(SVSD). (2014a). FRS, 2012-2013 [DC]. UKDA. SN: 7556, https://doi.org/10.5255 /UKDA-SN-7556-1.

DWP, NatCen, ONS(SVSD). (2014b). FRS, 2011-2012 [DC]. 2nd Edition. UKDA. SN:7368, https://doi. org/10.5255/UKDA-SN-7368-2.

DWP, NatCen, ONS(SVSD). (2014c). FRS, 2010-2011 [DC]. 2nd Edition. UKDA.SN:7085 https://doi. org/10.5255/UKDA-SN-7085-2.

DWP, NatCen, ONS(SVSD). (2014d). FRS, 2009-2010 [DC]. 3rd Edition. UKDA. SN:6886, https://doi. org/10.5255/UKDA-SN-6886-3.

DWP, NatCen, ONS(SVSD). (2014e). FRS, 2008-2009 [DC]. 3rd Edition. UKDA. SN:6523, https://doi. org/10.5255/UKDA-SN-6523-3.

DWP, NatCen, ONS(SVSD). (2014f). FRS, 2007-2008 [DC]. 2nd Edition. UKDA. SN:6252, https://doi. org/10.5255/UKDA-SN-6252-2. 
DWP, NatCen, ONS(SVSD). (2014g). FRS, 2006-2007 [DC]. 3rd Edition. UKDA. SN:6079, https://doi. org/10.5255/UKDA-SN-6079-2.

DWP, NatCen, ONS(SVSD). (2014h). FRS, 2005-2006 [DC]. 2nd Edition. UKDA. SN:5742, https://doi. org/10.5255/UKDA-SN-5742-2.

DWP, NatCen, ONS(SVSD). (2016). FRS, 2014-2015 [DC]. UKDA.SN:8013, https://doi.org/10.5255 /UKDA-SN-8013-1.

DWP, NatCen,ONS(SVSD). (2016). FRS, 2013-2014 [DC]. 2nd Edition. UKDA. SN:7753, https://doi. org/10.5255/UKDA-SN-7753-2.

DWP, NatCen, ONS(SVSD). (2017). FRS, 2015-2016 [DC].UKDA.SN:8171, https://doi.org/10.5255 /UKDA-SN-8171-1.

DWP, ONS(SVSD), NatCen. (2016). FRS, 2005/06-2015/16 and HBAI, 1994/95-2015/16: Safe Room Access [Data Collection (DC)]. 6th Edition. UKDA. SN:7196, https://doi.org/10.5255/UKDA-SN-7196-8

ONS.(2016). Crime survey for England and Wales, 1996 2015: Secure access [DC]. UK Data Service. SN: 7280 .

University of Essex. ISER, NatCen social research, kantar Public. (2017). Understanding Society: Waves 1-6, 2009-2015 [DC]. UK Data Service. SN: 6614.

\section{Affiliations}

\section{Polly Vizard ${ }^{1} \cdot$ Polina Obolenskaya $^{1} \cdot$ Tania Burchardt $^{1}$}

Polina Obolenskaya

P.Obolenskaya@1se.ac.uk

Tania Burchardt

T.Burchardt@1se.ac.uk

1 Centre for Analysis of Social Exclusion, London School of Economics, London, UK 